\title{
Denial of Causality by Hume and Answer of Commentators of Transcendent Wisdom of Mulla Sadra
}

\author{
MOHSEN MARVINAM ${ }^{1}$
}

\begin{abstract}
Hume divides all propositions into two parts: the relations of ideas and matters of fact. He considers the first part certain and matters of fact that makes us aware of the future and can take us beyond sensory perception are uncertain. He believes all reasoning about matters of fact is based on the relation of cause and effect and the principle of uniformity of nature. Based on his especial epistemology, argues that the principle of causality is a mental habit and the principle of uniformity of nature is matter of facts must be proved by experience that its proof and argument is probable that leads to a circle and ultimately expresses his skepticism. Commentators of transcendent wisdom based on the intuitive knowledge of the soul in its own works and actions, proved the idea of causality. They have discussed the unity of sensory and sensible theory, along with the principle of self-evident of causality that these theories only explain the origin of the concept of causality and its generality. However, the main question is how can causality be attributed to objective instances? In response, we have discussed the combination and sum of reason and sense using the experimental method.
\end{abstract}

Keywords: causality, David Hume, Mulla Sadra, skepticism, transcendent wisdom

David Hume (1711-1776) is generally considered as the most important philosopher in English and the last of the great triumvirate of "British empiricists" challenged traditional philosophical beliefs in ways that influenced the readers of his day. He based on the conditions of his time and the changes that had taken place in the philosophers' attitudes before him towards metaphysical concepts, set out the epistemological themes, and discussed the way in which human perceptions formed. Finally, by confining knowledge in experiential and sensory perception, concluded that causality is a subjective and mental habit that has no reality beyond the bounds. The exponents of Mulla Sadra's philosophy or transcendent wisdom such as Allameh Tabatabai and Motahhari, based on their specific epistemological foundations rooted in the history of Islamic philosophy, responded to Hume's doubts and rejection of the principle of causality. Like Hume, they accept that the concept of causality is not directly derived from sensory perception. However, the reason, by examining the relationships between sensory perceptions,

In this paper, we discuss Hume's epistemological viewpoints and his theory of causality and then based on Mulla Sadra's epistemological foundations (Transcendent Wisdom), present and respond to his skepticism.

\section{Hume's Epistemology}

Epistemology is a field of philosophy that concerns with the nature and process of how knowledge is acquired (Allen 1991: 45). Hume developed epistemology more fully by applying the scientific

\footnotetext{
1 Mohsen Marvinam, Ph.D., Assistant Professor of Islamic Philosophy, Department of Philosophy and Islamic Wisdom, Faculty of Theology and Islamic Studies, Meybod University, MEYBOD, Yazd, Iran, email: mohsenmarvinam@gmail.com.
} 
methods of observation to a study of human nature itself. His main goal was to establish a science of human nature that will put philosophy on a solid foundation of experience and observation.

From Hume's point of view, human nature is the capital or center of science (Capleston 1994: 245). George Edward Moore argues that Hume has pursued a central theme in both of his books that are about human understanding and it is the discovery of the limits and powers of human comprehension; thereby giving us a detailed analysis of his talents and capacities (More 2000:132). Hume seeks out how the mind functions and deduces its inference and reasoning, in other words, it seeks the science of human nature. He wants to incorporate Newton's method, which had some profound advances in physics, into philosophy. He says," There is no reason to despair of equal success in our enquiries into the powers and organization of the mind "(Hume 1975, 1: 9). For Hume, the science of human nature must be based on observing the functioning of the human mind (Maggie 2000: 234).

Given that, Hume regard the principle of causality as the basis for any kind of reasoning and deduction through which one can go beyond observation and the senses to inform the unseen things in the future and it is the basis of general rules in the sciences; based on his empiricism principle, he has criticized causality (Hume 1978: 74). Based on his special analysis of nature and within man, considers the concept of necessity to have been constructed by the mind, not a real and objective thing that originated from the reality that we would discuss it later. Therefore, Hume first discusses and describes how ideas are formed, and then discusses how propositions about real things in science are formed and how the truth of propositions is proved.

He chose experience-based and empirically proven as a criterion for the separation of difficult and ambiguous philosophy from easy philosophy. The priority of impressions to ideas is the criterion for determining whether a philosophy is based on experience and observation or not. That is, every philosophy and science has its own issues and concepts, if these ideas and concepts have impressions priority to themselves, then that philosophy can be accepted as science; otherwise, that philosophy is complex, and worthless, and must be rejected.

To criticize the content of cognition, Hume puts forward principles that help us to identify ambiguous ideas or principles from clear ideas or principles. In fact, after examining Hume's theories, we find that the three basic principles form Hume's skepticism and perhaps Hume's philosophy is: the priority of impressions to ideas, Hume's fork and the association of ideas. We criticize these principles from two perspectives: First, from the point of view of their contradiction with the principles that accepted by Hume. Second, from the perspective of the solutions proposed by Islamic philosophy; especially by the commentators of Mulla Sadra or Transcendent Wisdom.

\section{The Copy and Association Principle}

Hume, In order to separate ambiguous and meaningless ideas from other concepts, puts forward his own theory of the origin of imagination and divides all perceptions of mind into two classes, on the basis of their different degrees of force and liveliness. Impressions are the direct, vivid, and forceful products of immediate experience and ideas are merely feeble copies of these original impressions .He says "By the term impression, I mean all our more lively perceptions when we hear, see, feel, love, hate, desire, or will” (Hume 1975, 2: 12). In Islamic philosophy impression is called primary rational, as opposed to secondary rational concepts. These are to be distinguished from ideas, which are the fainter perceptions of which we are conscious when we reflect on or look inwards at our impressions. For example, the background color of the screen at which I am now looking is an impression, while my memory of it is an idea. Hume offers this "general proposition" as his "first principle in the science of human nature" (Hume 1978: 7); which has become known as the "copy principle"

So when we come to suspect that a philosophical term is being used without any meaning or idea (as happens all too often), we need only to ask: From what impression the supposed idea 
is derived. If none can be pointed out, that will confirm our suspicion that the term is meaningless. By bringing ideas into this clear light, we may reasonably hope to settle any disputes that arise about whether they exist and what they are like (Hume 1975, 2: 17).

Hume believes that the mind's thoughts or ideas are obviously inter-connected in some systematic way and there is some order and regularity in how, in memory and imagination, one idea leads on to another.

He says "yet I have not found any philosopher trying to list or classify all the sources of association. To me there appear to be only three factors connecting ideas with one another, namely, resemblance, contiguity in time or place, and cause or effect." (Hume 1975, 3: 19).

Given that, Hume's main concern with causality is the origin of the conception of causality, Hume's answer is that the conception of causality must be derived from a connection between objects. In fact, of the three connections and ratios of resemblance, contiguity in time or place and the essential connection between cause and effect, he considers the necessity connection between cause and effect play a central role in forming the conception of causality. Moreover, he asks, how can we just be satisfied in terms of repetitions and sequences, or priority of thing to other? Then suppose we get a complete conception of causality? This is not possible at all; there may be things that are side by side with other things without causal connection. Causality should be considered a necessity connection between cause and effect, and this necessity connection is much more important than two previous factors? (Hume 1978: 77). This is where Camp Smith emphasizes on the role of the essential distinction in Hume's causality theory that Hume considers causality to be a form of relationship, that its essential distinction is connection between cause and effect (Smith 1941: 369)

\section{Hume's Fork Principle}

Hume believes that humans often accept beliefs that they cannot be truthful and justified. He wants to show what is characteristic of beliefs that we can justify them. To this end, he divides the proposition and all the objects of human reason or enquiry into two groups: 1 . The relations of ideas, and 2. Matters of fact. This is called Hume's fork. The first kind includes geometry, algebra, and arithmetic, and indeed every statement that is either intuitively or demonstratively certain; Such as three times five equals, half of thirty expresses a relation between those numbers. These propositions are nowadays called analytic propositions.

Matters of fact, , are not established in the same way; and we cannot have such strong grounds for thinking them true. He divides propositions related to matters of fact into two categories: one that expresses the things that we are now observing or reflects the events that we have observed and now remember them. With regard to these propositions, we have a direct observation of the senses or the expression of memory. Second, propositions we do not observe now, not in the past.

From George Edward Moore's point of view, Hume's main concern is the second part of the propositions of matters of fact that we have not directly observed; In this regard, Hume is interested in how we can prove the validity and authority of these propositions (Moore 2000: 149). The contrary of every matter of fact is still possible, because it does not imply a contradiction and is conceived by the mind as easily and clearly as if, it conformed perfectly to reality. That the sun will not rise tomorrow is just as intelligible as - and no more contradictory than - the proposition that the sun will rise tomorrow (Hume 1975, 4: 20-21). These propositions are nowadays called synthetic propositions.

\section{Hume's Analysis of Causality}

Hume believes all reasoning about matters of fact is based on the relation of cause and effect, which is the only relation that can take us beyond the evidence of our memory and present senses. 
In fact, it is the basis of all the laws of science of the empirical sciences, and scientific predictions are possible by means of it. when we ask someone why he believes some matter of fact, which is not now present to him for instance that his friend is now in France (Or, for example, God exists) he will give us a reason; and this reason will be some other fact, such as that he has received a letter from his friend. All reasoning concerning fact is like this. Since we reason in this way, we suppose that the present fact is connected with the one that we infer from it.

Therefore, if we want to understand the basis of our confidence about matters of fact, we must find out how we come to know about cause and effect. Moreover, knowledge about causes is never acquired through a priori reasoning, and always comes from our experience of finding that particular objects are constantly associated with one other. When it is further asked, what is the foundation of all our reasoning about cause and effect? The answer is "experience" (Hume 1975, 4: 28)

The connection between a proposition that summarizes past experience and one that predicts what will occur at some future time can only be established by adding a premise stating that nature is uniform, however how could we justify such a claim? Appeal to experience will be circular; since all reasoning is either demonstrative or probable, there is no good demonstrative argument of any kind for uniformity of nature and the contrary of uniformity of nature can be distinctly conceived and is possible.

Therefore, arguments about existence and matters of fact are based on the relation of cause and effect; is derived entirely from experience; and in drawing conclusions from experience, we assume that the future will be like the past (the principle of uniformity of nature). If we try to prove this assumption by probable arguments, i.e. arguments regarding existence and matter of facts, we shall obviously be going in a circle and ultimately we cannot prove it (Hume 1975, 4: 30) Consequently, in Hume's view, the causality principle is uncertain and cannot be the basis of scientific laws and we cannot predict future events.

The most important criticism of Hume's analysis of causality is that the division of all reasoning into the relation of ideas and matters of Facts in which category fits. It is clear that this division is not part of the relation between ideas, which is intuitively certain, but is a matter of fact that can be denied and doubted, and so the criterion itself can be denied; in other words, Hume actually defeats himself using his own weapons.

\section{Necessary Connection}

In Hume's view, the necessary connection between cause and effect plays the most important role in forming the concept of causality because merely the repetition and contingent of events together, cannot give us an accurate conception of causality. In addition, based on his epistemology, he continues his argument with the question of which impression, the idea of the necessary relation arises. Moreover, he expresses his concern, "Why do we conclude that particular causes must necessarily lead to particular effects?"(Hume 1978: 78).

In his negative approach based on his own empirical principles and the principle of copy, he says that since we have no impression to the idea of a necessary connection, then this idea is meaningless and in his positive approach, he considers this necessary connection the result of the mental habit and the necessary structure of human nature and mind.

Hume in his positive approach says:" having found in many cases that two kinds of objects-flame and heat, snow and cold, have always gone together, and being presented with a new instance of flame or snow; the mind's habits lead it to expect heat or cold. Believing that heat or cold exists now and will be experienced if one comes closer is the necessary result of placing the mind in such circumstances. Therefore, these operations of the soul are a kind of natural instinct, which no reasoning or process of the thought and understanding can either produce or prevent. (Hume 1975: 5, 38). In fact, Hume here refers to a psychological fact that our minds have a mechanism by which one image absorbs the other. Moreover, this mechanism accompanies our 
causal beliefs in various ways. Helen Beebe calls this mechanism an associative mechanism of causation (Beebe 2006: 16).

\section{Epistemology in Islamic Philosophy and the Transcendent Wisdom of Mulla Sadra}

The subject of epistemology was subordinate to other issues such as the division of the powers of the soul into stimulating forces and perceptual forces, subjective existence against objective existence and in the logic, the truth and falsehood of propositions etc.

On the question of how truthfulness and meaningfulness of philosophical propositions are, among the various theories of truth and meaningfulness of propositions, the Muslim philosophers have put forward the theory of correspondence of truth or conformity of the proposition to the reality (objective or subjective truth) that its history goes back to Plato's Sophistic and Aristotelian metaphysics (Carr 1988: 79). In Islamic philosophy, philosophical ideas and propositions, although not directly derived from the senses (impressions), but intellect (reason power) uses impressions and comparing them with one another, make philosophical concepts and propositions, such as the concept of causality that the truth and falsity or meaning of these propositions can be proved or rejected by reason. It is worth noting, however, that what Hume considers to be probable, and refutable among matters of fact is called "incomprehensive induction" versus "comprehensive induction" in the science of logic. In the science of logic, incomprehensive induction is not accepted as a precise and comprehensive argument; because we have certain knowledge in relation to particular cases not all cases of world. Rather, this argument must be accompanied by a rational argument to allow the use of imperfect induction. However, Hume denies the role of reason in knowledge.

\section{Causality in Islamic Philosophy and the Transcendent Wisdom of MullaSadra}

In Islamic philosophy, the main and predominant approach of Muslim philosophers to causality is ontological approach; as Mulla Sadra states in the definition of causality "The effect always derives its existence from cause and if that is not the cause, then the effect will not be necessary" (Mulla Sadra 1360: 69). On the contrary, Hume's approach and his definition of causality is an epistemological approach.

Hume and Muslim philosophers share this point that the concept or idea of causality is not directly derived from sense, and what is sensible is only sequencing two things in outside. Even Avicenna in the book of Shefa, explicitly says that if one suspects that causality and the relation of cause and effect are understood and acquired through sense, it is mistaken (Avicenna 1418: 18). On the Importance of the Sense and Position of Sensory Perception in Islamic Philosophy, not only Avicenna believes that human beings were created in such way that science and perception are naturally performed through the senses (Avicenna 1379: 19); But also Mulla Sadra believes human perceptual activity begins through the senses. And all rational concepts (ideas) are derived from sensory impressions (Mulla Sadra 1981, 4: 300). Hume even rejected the self-evident of causality; as all his claims are based on an epistemological principle, which this principal was great emphasis on sensitivity and this point that all our beliefs about the objective things are derived from experience (Beauchamp 1991: 22).

In the position of final judgment and evaluation, as Hume admits, our minds follow ideas according to rational rules and principles; and the structure of the mind is not disordered and chaotic, and this association of ideas is based on the objective and outside world. Because if there was no rational and logical connection between phenomena in the objective world; the mind would not understand this rational and logical relation. The most subtle point is that Hume has reduced this logical relationship to a mental habit and a psychological matter that has no truth in the objective world (Khademi 1380: 267). Indeed, Hume's way of explaining causality based on his own epistemological issues confronts him with serious ontological problems. So if causality is 
not a real matter and is purely made by the mind, in the objective world there really should be no causality, which means that there is no guarantee that (for example) we can harvest bananas when we plant tree of bananas or when we eat food, we can be full. In addition, the result is a chaos that Hume himself does not accept in the realm of practical life.

\section{Causality Based on Transcendent Wisdom}

We attempt to analyze how the idea of causality emerges in the mind And how it applied based on the epistemological and ontological foundations of Mulla Sadra's philosophy. Motahhari, who is a well-known exponent of Mulla Sadra's philosophy, says: "Philosophical discussion of objective reality and the world is impossible before knowing the mind and the quality of the conceptualization of the mind, so we cannot have philosophy until we know the mind." (Motahari 1374, 3: 220). After translating Hume's works and his critique of the principle of causality, the commentators of Mulla Sadra's philosophy sought to prove the idea of causality. In addition, how it emerged in the mind and its application in science in a way other than sense and experience, and ultimately they have responded to Hume's criticism.

First, we specifically refer to the theories of Allameh Tabataba'i and Motahhari, in which these two Muslim philosophers, apart from seeing the principle of causality as a self-evident and rational principle, have proved causality in their own works through intuitive science and Selfknowledge of soul to his own effect and actions. Then based on the foundations and contents of transcendent wisdom, we come to another theory, which we call the unity of sensory and sensible theory or the presence of the soul in the place of sensory powers. So here, we generally prove in two ways how the concept of causality was formed in the mind: 1. Self-knowledge of soul to his own effect and actions, and; 2- The unity of sensory and sensible (sensorial known) theory or the presence of the soul in the place of sensory powers.

\section{Proof of Causality Based on the Self-Knowledge of Soul to His Own Effect}

Muslim philosophers saw causality as a self-evident subject and considered the causality to be a secondary philosophical concept (idea), but how this concept is formed in the mind and how it applied to external and objective worlds, had no argument. Until Tabatabai first discussed this issue in the book "Principles of Philosophy and the Method of Realism" then Motahari described it in the margins and footnotes of this book (Motahari 1374, 2: 23).

He argues that we perceive within ourselves both the existence of the soul (self) and the dependence of the effects of the soul (self) on itself by intuition. In this sense, we find intuitively (by intuitive science) that the soul is the cause of thought, will, judgment, and various other things. Thus, if the soul does not want something, it will not exist. It mean that thought, will, and other things are actually dependent on the soul. After an intuitive and intrinsic understanding of the concept of causality, we can transmit it to objectives and external instances (Motahari 1374, 2: 77-79; Tabatabai 1373: 76).

\section{Proof of Causality Based on the Unity of Sensory and Sensible Theory}

Sensory perceptions are of two types: 1 . Sensory perception of things that cause and effect are both objective and external and out of our minds, like seeing billiard balls collides with each other in Hume's example, and; 2. Sensory perception of things that cause and effect are not objective and external; One is external (cause) and the other (effect) is directly related to the sensory powers. Such as biting a scorpion on skin or tasting orange in the tongue.

In the first type of sensory perception, such as seeing billiard balls in Hume's example, it is right to deny the possibility of sensory perception of causality; because in this type of sensory perception only the association or pursuit of two things can be understood; not the existential 
relation between objects. However, in sensory perception of the second kind, such as scorpion sting or taste of orange, we sense two things simultaneously through sensory powers. One is the effect (pain caused by scorpion sting or taste of the fruit) and the other is the connection of the effect into the effecter or agent cause. Finally, from this connection, the concept or idea of causality is understood by reason (Ahmadi 1388: 145-147).

It is clear that the scope and validity of these two theories are limited to the perception of things that are in one aspect related to the objective world, and in the other, to the soul or both aspect of them are in the soul (spirit). However, the key question is how do we apply and attribute causality to things that both aspects of them are external and objective? How do we apply the idea of causality that we perceive within our own selves (within own soul) to the objective things and outside of ourselves? It is here that we must point to self-evident of the principle of causality. Finally, for the application of causality in the outside world and objectives things, we should apply (combine) both reason and sense.

Throughout the history of Islamic philosophy, almost all Muslim philosophers have held that the principle of causality is a self-evident principle and reasonable rather than sensible (Avicenna 1418: 8). Given that, the principle of causality is reasonable, not sensible, and its application to the objective instances cannot be justified and explained by intuitive science of the soul. On the other hand, we have no choice, but to apply it to different sciences (Experimental sciences) and practical life; so, what is the origin of the idea of causality?

In answering this question, we are confronted with the self-evident of causality. Even Hume, who seeks to reduce causality to a mental habit, first expresses the premises and then draws his own conclusion that here he unconsciously applies the principle of causation. For this reason, he gives his audience the right to return to their former beliefs about the external world, after studying his skepticism (Russell 1351: 317). In Hume's view, human beings cannot adhere to the practical results of general skepticism and apply it in real life (Fogelin 2009: 226).

To conclude, Hume argues that because the propositions of matters of fact are based on the principle of causality and the principle of uniformity of nature, we cannot accept the truthfulness and certainty of these propositions. On the other hand, the principle of causality is a mental habit and the principle of uniformity of nature is matter of facts must be proved by experience. Moreover, this proving and argument is a probable argument that ultimately leads to a circle. Therefore, Hume, with such an argument, violates the basis of all claims concerning the future and the unseen things (metaphysical concepts) and expresses his skepticism. In fact, Hume cannot prove with certainty that the contrary of matters of facts is correct. He can only express the probability of these propositions is true. As a result, in this way he makes skepticism. In response to the skepticism of Hume, the commentators of transcendent wisdom, based on their own epistemology, responded to his skepticism in two steps:

In the first step, they have argued about the origin of the concept (idea) of causality that we intuitively understand the cause of the soul for its own works and actions (will, decision etc.) within ourselves, and then attribute that concept to objective facts. On the other hand, through the theory of unity of sensory and sensible, we understand the effect of external objects on the sensory organs that if there were no effect of the external objects, there would be no sensory perception. In fact, the effect of external objects is "cause" and sensory perception is "effect". Consequently, we understand intuitively the necessity connection of effect to the agent cause or effecter.

In the second step, it has been argued that the principle of causality is a self-evident and does not need to be proved that can be regarded as propositions of the relations of ideas that cannot be contradicted. In a way that Hume has also unconsciously accepted in his arguments, thus the application of the principle of causality in the objective world and empirical sciences is possible through the combination (sum) of sense and reason. 


\section{References}

Ahmadi, Ahmad. 1388. The Basic Layers of Recognition (Bon Layhiay Shenaght). Tehran: Samt Publication.

Allen R. E. 1991. Greek Philosophy: Thales to Aristotle. 3rd Ed. New York: The Free Press.

Avicenna. 1379. Al-Talighat. Qom: Bustan Book Publication.

Avicenna. 1418. Theology Book of Shefa. Researched by Hassan Hassanzadeh Amoli. Qom: Center Publication of Qom.

Beauchamp, T. L. \& A. Rosenberg. 1991. Hume and the Problem of Causation. New York: Oxford University Press.

Beebe, Helen. 2006. Hume on Causation. Canada: Routledge.

Bryan, Magee. 2000. The Great Philosophers: An Introduction to Western Philosophy. Oxford: Oxford University Press.

Carr, Brian. 1988. Truth. In, An Encyclopedia of Philosophy. G. H. R. Parkinson (ed.). London: Routledge.

Copleston, Fredric. 1994. A History of Philosophy. Volume 5. New York: Image Books.

Fogelin, Robert J. 2009. Hume's Skepticism. In, The Cambridge Companion to Hume. Edited by David Fate Norton \& Jacqueline Anne Taylor. London: Cambridge University Press.

Hume, David. 1975. Enquiries Concerning Human Understanding and Concerning the Principle of Morals. Edited by L. A. Selby-Bigge \& Revised by P. H. Nidditich. Oxford: Clarendon Press.

Hume, David. 1978. A Treatise of Human Nature. Edited by L. A. Selby-Bigge \& Revised by P. H. Nidditch. London: Oxford University Press.

Khademi. 1380. Causality from the Point of View of Muslim Philosophers and Empiricist Philosophers. Qom: Bustan Publication.

Kuehn, M. 1983. Kant's conception of Hume's problem. Journal of the History of Philosophy 21: 175-93.

More, G. E. 2000. Philosophical Studies. London: Routledge.

Motahari Morteza. 1374. The Principles of Philosophy and the Method of Realism (Osu Phalsafe Va Ravesh Realism). Vol. 1, 2, 3 . Tehran: Sadra Publication.

Mulla Sadra. 1360. Al-Shvahedo Al-Rubaiya fi al-Manahaj al-Sulukia. Corrected by Sayyed Jalal AlDin Ashtiani. Mashhad: Publishing Center.

Mulla Sadra. 1375. Collection of Mulla Sadra's Philosophical Treatises. Corrected by Hamed Naji Esfahani. Hekmat Publications.

Mulla Sadra. 1981. Al-Hikma al-Mutalliyyah fi al-Asfar al-Arba'a al-Aqiliya. Vol. 1-9. 3rd edition. Beirut: Dar Al-Hayaa Al-Tharat Publications.

Russell, Bertrand. 1351. The History of Western Philosophy and its Relations with Political and Social Situation from Ancient to Present. Translated by Najaf Daryabandari. n.l.: Pocket Book Publishing.

Smith, Kemp, N. 1941. The Philosophy of David Hume: A Critical Study of its Origins and Central Doctrines. London: Macmillan.

Tabatabai Mohammad Hussein. 1385. Nahaito al-Hikma. Qom: Boston Book Publishing. 